\title{
Suramin potently inhibits cGAMP synthase, CGAS, in THP1 cells to modulate IFN- $\beta$ levels
}

\author{
Modi Wang ${ }^{1,2}$, Moloud A Sooreshjani ${ }^{1,2}$, Clinton Mikek ${ }^{1,2}$, Clement Opoku-Temeng ${ }^{1,3}$ \& \\ Herman O Sintim*,1,2 \\ ${ }^{1}$ Purdue Institute for Drug Discovery, Department of Chemistry, Purdue Institute of Inflammation, Immunology \& Infectious \\ Disease, Purdue University, West Lafayette, IN 47907, USA \\ ${ }^{2}$ Department of Chemistry, Purdue University, West Lafayette, IN 47907, USA \\ ${ }^{3}$ Biochemistry Graduate Program, University of Maryland, College Park, MD 20742, USA \\ *Author for correspondence: hsintim@purdue.edu
}

\begin{abstract}
Aim: Persistent activation of STING pathway is the basis for several autoimmune diseases. STING is activated by cGAMP, which is produced by cGAS in the presence of DNA. Results/methodology: HPLC-based medium throughput screening for inhibitors of cGAS identified suramin as a potent inhibitor. Unlike other reported cGAS inhibitors, which bind to the ATP/GTP binding site, suramin displaced the bound DNA from cGAS. Addition of suramin to THP1 cells reduced the levels of IFN- $\beta$ mRNA and protein. Suramin did not inhibit lipopolysaccharide- or Pam3CSK4-induced IL-6 mRNA expression. Conclusion: Suramin inhibits STING pathway via the inhibition of cGAS enzymatic activity. Suramin or analogs thereof that displace DNA from cGAS could be used as anti-inflammatory drugs.
\end{abstract}

First draft submitted: 21 December 2017; Accepted for publication: 5 March 2018; Published online: 21 March 2018

Keywords: 2', 3'-cGAMP • autoinflammatory disease • cGAS • STING • suramin

The presence of nucleic acid in the cytoplasm induces a strong immune response via activation of the cGASSTING pathway [1]. DNA in the cytoplasm is recognized by cyclic GMP-AMP synthase (cGAS), which catalyzes the synthesis of the signaling molecule $2^{\prime} 3^{\prime}$-cGAMP (cGAMP) from ATP and GTP [1]. cGAMP binds to the stimulator of interferon (IFN) genes (STING) and triggers a type I IFN response (Figure 1) [2]. Although activation of the cGAS-STING pathway plays a key role in host-pathogen interaction [3,4], persistent activation of cGAS by endogenous DNA can result in autoinflammatory disorders [5]. cGAS has been reported to stimulate cytokine production in Trex $1^{-/}$deficient mice, which results in inflammation and death. Furthermore, cGAS deletion in Trex $1^{-/}$mice can rescue mice from lethal autoimmune phenotypes (Figure 1) $[5,6]$.

When DNA is present in the cytosol, it is an indication of damage (such as DNA leakage from the nucleus or mitochondria) [12] or the DNA could be a danger signal from an invading virus or bacteria [13]. Cytosolic DNA may be degraded by the exonuclease TREX1 [13-15] or it can interact with cGAS, leading to the activation of cGAS to produce $2^{\prime}, 3^{\prime}$-cGAMP, which binds to and activates STING $[4,16]$. STING, an endoplasmic reticulum adaptor protein [17], activates TBK1, which phosphorylates IRF3 (Figure 1) [18]. Phosphorylated IRF3 dimerizes and crosses into the nucleus, where it associates with the IFN- $\beta$ gene and, with c-Jun and ATF-2, facilitates the expression of the IFN- $\beta$ mRNA, which ultimately leads to increased levels of IFN- $\beta$ protein [19-21]. This results in a type I IFN immune response (Figure 1) [13]. If DNA is not cleared from the cytoplasm, for example, in instances whereby TREX1 is inactive due to mutation, the type I IFN immune response may be persistently activated and lead to autoimmune diseases such as Aicardi-Goutières syndrome (AGS) and lupus [14-15,22].

Efforts are underway by a number of research groups to develop new inhibitors of cGAS or to repurpose current drugs for cGAS inhibition. Recently, several antimalarial drugs were screened in silico using mouse cGAS/DNA target (PDB 4LEZ) to identify compounds that inhibit cGAMP synthesis. The identified cGAMP synthesis inhibitors, hydroxychloroquine, quinacrine (QC) and 9-amino-6-chloro-2-methoxyacridine (ACMA), which inhibited cGAMP synthesis with micromolar $\mathrm{IC}_{50}$ values, did not bind to the active site of cGAS but were instead found to localize to the minor groove of DNA between the cGAS/DNA interface [23]. 


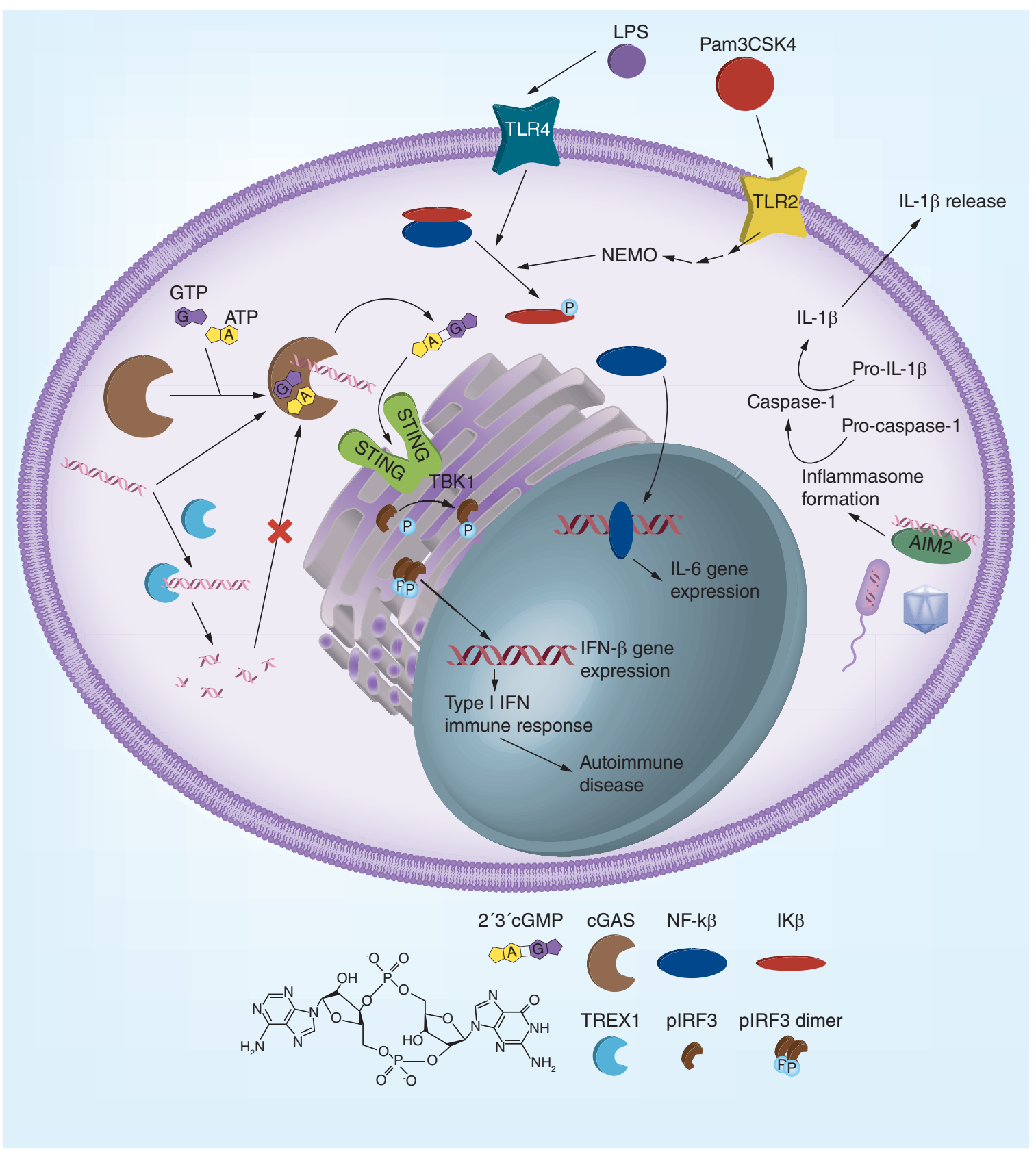

Figure 1. Schematic representation of CGAS-STING pathway and its role in autoimmune disease. Also shown are condensed pathways for activation of TLR pathways by LPS [7] and Pam3CSK4 [8] to activate IL-6 gene expression via $\mathrm{NF}-\kappa \beta$ [9] and the inflammasome-mediated activation of IL-1 $\beta$ [10] via caspase-1 [11]. LPS: Lipopolysaccharide; TLR: Toll-like receptor.

Recently, other small molecules, such as RU.521 and RU.365, were found to be inhibitors of cGAS [24]. Unlike the antimalarial compounds that bound to the DNA in the cGAS/DNA complex, the crystal structure of RU.365 in complex with mouse cGAS/dsDNA complex indicated that these new cGAS inhibitors acted at the cGAS active site [24]. RU.521 displayed activity in a cellular assay. Using a novel fluorescence polarization assay, a Pfizer group identified PF-06928215 as a potent inhibitor of human cGAS activity $\left(\mathrm{IC}_{50}=4.9 \mu \mathrm{M}\right)$. PF-06928215, however, displayed no activity in cellular cGAS assays measuring dsDNA-induced IFN- $\beta$ expression [25].

In our ongoing efforts to identify small molecule inhibitors of cyclic dinucleotide metabolism enzymes [26-28], we have also been trying to identify inhibitors of cGAMP synthesis by cGAS. Here, we disclose that suramin, which is 
on the WHO list of essential drugs for the treatment of river blindness and African sleeping sickness [27], potently inhibits the formation of $2^{\prime}, 3^{\prime}$-cGAMP by human cGAS/DNA complex.

\section{Materials \& methods}

The fluorescently labeled and unlabeled 100-bp dsDNA (HPLC-purified) were obtained from Midland Certified Reagent Company, Inc. (TX, USA). DNA gel electrophoresis indicated that the purchased DNA was pure. Primers for reverse transcription polymerase chain reaction (RT-PCR) were purchased from Integrated DNA Technologies, Inc. (IL, USA). Suramin sodium salt ( $\geq 99 \%)$, Deoxyribonucleic acid sodium salt from herring testes, lipopolysaccharides (phenol extraction), Poly(I:C) ( $\geq 99 \%)$, proflavine hemisulfate salt hydrate and diminazene aceturate (analytical standard) were purchased from Sigma-Aldrich (MO, USA). Pam3CSK4 was purchased from Invivogen (CA, USA). Lipofectamine ${ }^{\circledR}$ LTX with Plus ${ }^{T M}$ Reagent, SuperScript ${ }^{T M}$ II reverse transcriptase, random hexamers, DAPI were purchased from Thermo Fisher Scientific (MA, USA). Aurum ${ }^{\text {TM }}$ Total RNA Mini Kit was purchased from Bio-Rad (CA, USA). Deoxynucleotide (dNTP) Solution Mix was purchased from New England Biolabs (MA, USA). QuantiTect SYBR ${ }^{\circledR}$ Green PCR Kit was purchased from QIAGEN (MD, USA). All reagents were used as purchased without further purification unless specified.

\section{Cell culture methods \& maintenance}

THP1-Dual $^{\mathrm{TM}}$ cells and THP1-Dual KO-cGAS cells were purchased from InvivoGen. Cells were cultured in RPMI 1640 containing 10\% heat inactivated FBS, $10 \mathrm{mM}$ HEPES, $2 \mathrm{mM}$ glutamine, $100 \mathrm{U} / \mathrm{mL}$ penicillin and $100 \mathrm{mg} / \mathrm{mL}$ streptomycin, and maintained at $37^{\circ} \mathrm{C}$ under $5 \% \mathrm{CO}_{2}$. All reagents and medium were purchased from Fisher Scientific, (PA, USA) unless otherwise noted. Cells were cultured in EMEM containing 10\% FBS and $10 \mathrm{mM}$ HEPES. EMEM was purchased from ATCC (VA, USA).

\section{Expression \& purification of hc GAS}

Full-length human 6xHis-MBP-tagged plasmid was donated by the Doudna lab [29]. cGAS was expressed in BL21-RIL DE3 along with pRARE2 human tRNA plasmid. hcGAS was purified as previously described with slight modification. Briefly, bacteria were grown in $2 \mathrm{XYT}$ media at $37^{\circ} \mathrm{C}$ to an $\mathrm{OD}$ (optical density at 600 $\mathrm{nm}$ ) of approximately 0.6 and induced with $0.5 \mathrm{mM}$ IPTG for $20 \mathrm{~h}$ at $16^{\circ} \mathrm{C}$. Cells were sonicated in lysis buffer containing $20 \mathrm{mM}$ Tris- $\mathrm{HCl}$ ( $\mathrm{pH}$ 7.5), $400 \mathrm{mM} \mathrm{NaCl}, 10 \%$ glycerol, $30 \mathrm{mM}$ imidazole and $1 \mathrm{mM}$ PMSF. The protein was passed through a HisTrap HP $1 \mathrm{~mL}$ column and washed with lysis buffer. hcGAS was eluted with lysis buffer supplemented with $300 \mathrm{mM}$ imidazole [29]. TEV protease was added to the eluted cGAS to remove the His-MBP tag. The mixture was passed through a HisTrap HP $1 \mathrm{~mL}$ column to purify the cGAS from the His-MBP tag [30]. cGAS protein purity is shown in Supplementary Figure 1.

\section{cGAS HPLC activity assay}

Assay was performed as described previously with slight modifications [29,31]. The reaction mixture included $20 \mu \mathrm{M}$ library compound, $3 \mu \mathrm{M}$ enzyme, $200 \mu \mathrm{M}$ ATP, $200 \mu \mathrm{M}$ GTP, $10 \mathrm{mM} \mathrm{MgCl}_{2}, 5 \mathrm{mM} \mathrm{CoCl}_{2}$ and $0.1 \mathrm{mg} / \mathrm{mL}$ herring testes-DNA (HT-DNA) in $20 \mathrm{mM}$ Tris buffer ( $\mathrm{pH} 7.5$ ) and was incubated at $37^{\circ} \mathrm{C}$ for $2 \mathrm{~h}$. HPLC analysis was used to detect cGAMP, the product of cGAS activity [29]. To identify potential inhibitors of cGAS, we performed an initial screening with suramin and kinase inhibitors (see Supplementary Table 2 for commercial kinase inhibitors screened) utilizing HPLC. The Sigma Kinase and Sigma PDE compounds were from Sigma-Aldrich.

\section{Thin layer chromatography}

To verify cGAMP inhibition, we used a modified radioactive assay [29]. Briefly, the assay mixture contained $20 \mathrm{mM}$ Tris (pH 7.5), $200 \mu \mathrm{M}$ ATP, $200 \mu \mathrm{M}$ GTP, 11 nM ${ }^{32} \mathrm{P}-\mathrm{ATP}, 10 \mathrm{mM} \mathrm{MgCl}_{2}, 5 \mathrm{mM} \mathrm{CoCl}_{2}, 0.1 \mathrm{mg} / \mathrm{mL}$ HT-DNA and $20 \mu \mathrm{M}$ suramin (or an equivalent volume of water as control). The reaction was initiated by the addition of $3 \mu \mathrm{M}$ enzyme and was incubated for $2 \mathrm{~h}$ at $37^{\circ} \mathrm{C}$. The reaction was terminated by holding at $95^{\circ} \mathrm{C}$ for $5 \mathrm{~min}$. A $0.5 \mu \mathrm{L}$ aliquot of the reaction mixture was spotted onto a cellulose plate. Plates were developed using saturated $\left(\mathrm{NH}_{4}\right)_{2} \mathrm{SO}_{4}$ and $1.5 \mathrm{M} \mathrm{KH}_{2} \mathrm{PO}_{4}$ buffer $(1: 1.5$, v:v). The plates were dried and exposed to Molecular Dynamics Phosphor Imager Screen overnight. 


\section{Electrophoretic mobility shift assay}

Electrophoretic mobility shift assay (EMSA) was performed to interrogate the dsDNA-binding of cGAS, in the presence or absence of suramin in vitro. For the dsDNA-binding studies, $1 \mu \mathrm{M}$ 100-bp IFN-stimulatory dsDNA labeled with FAM was incubated with $5 \mu \mathrm{M}$ cGAS and incubated at room temperature for $1 \mathrm{~h} \mathrm{[23].} \mathrm{Suramin} \mathrm{was}$ added at concentrations of $0,1,10,100$ and $200 \mu \mathrm{M}$ and incubated for an additional $2 \mathrm{~h}$ at room temperature. The mixtures were resolved on a $6 \%$ polyacrylamide gel by electrophoresis and visualized using a FluorChem $\mathrm{R}$ system (Protein Simple, CA, USA).

\section{Effects of suramin on IFN- $\beta$ expression}

Cellular levels of IFN- $\beta$ were detected via a luminescence assay as previously described [24]. Briefly, $1.0 \times 10^{5}$ THP1Dual cells were seeded in RPMI 1640 according to the manufacturer's protocol in 24-well plates. THP1-Dual cells were transfected with $0.5 \mu \mathrm{g}$ of HT-DNA using Lipofectamine LTX with Plus Reagent (Thermo Fisher Scientific) in the presence of $200 \mathrm{nM}, 1 \mu \mathrm{M}$ or $5 \mu \mathrm{M}$ suramin. Each condition was replicated at least in triplicate. The cells were harvested after $24 \mathrm{~h}$ and lysed with Pierce ${ }^{T M}$ Luciferase Cell Lysis Buffer (Thermo Fisher Scientific). The QUANTI-LUC ${ }^{T M}$ luminescence assay (Invivogen) was performed to detect changes in IFN- $\beta$ expression according to the manufacturer's procedure. Plates were read using a Cytation ${ }^{\top \mathrm{T}} 5$ Multi-Mode Microplate Reader.

For mRNA analysis, $5.0 \times 10^{5}$ THP1-Dual cells were seeded in RPMI 1640 according to the manufacturer's protocol in 6-well plates. THP1-Dual cells were transfected with $2.5 \mu \mathrm{g}$ of HT-DNA using Lipofectamine LTX with Plus Reagent in the presence of $0.2,1$ or $5 \mu \mathrm{M}$ suramin. Each condition was replicated in triplicate. Cells were harvested $24 \mathrm{~h}$ post-transfection, and RNA was extracted by Aurum Total RNA Mini Kit. Total RNA was reverse transcribed using random hexamer primer and SuperScript II reverse transcriptase into cDNA. Real-time PCR was carried out with QuantiTect SYBR Green PCR Kits and run on a BIORAD C1000 Touch Thermal Cycler. The IFN- $\beta$ primer [32] used is listed in Supplementary Table 1. Target $C_{q}$ values were normalized to GAPDH $C_{q}$ values and used to calculate $\Delta \mathrm{C}_{\mathrm{q}}\left(\mathrm{C}_{\mathrm{q} \text { (target) }}-\mathrm{C}_{\mathrm{q}(\text { ref })}\right)$. The relative gene expression was obtained by $\Delta \Delta \mathrm{C}_{\mathrm{q}}$ calculation method. This is accomplished by normalization of a gene target with experimental treatment to an endogenous reference gene (GAPDH).

For the experiment of dsDNA transfection for $30 \mathrm{~min}, 5.0 \times 10^{5} \mathrm{THP} 1$-Dual cells were seeded and transfected with HT-DNA for $30 \mathrm{~min}$ using the same protocol. The media containing DNA was then removed and cells were washed with fresh media. Cells were then cultured in fresh media for $24 \mathrm{~h}$ in the presence of 0 or $5 \mu \mathrm{M}$ suramin. mRNA expression values were analyzed by the previously mentioned method.

\section{Effects of suramin on cellular cytokine expression}

$5 \mu \mathrm{M}$ suramin was co-incubated with $200 \mathrm{ng}$ Pam3CSK4 (Invivogen), $25 \mu \mathrm{g}$ Poly(I:C) or $100 \mathrm{ng}$ lipopolysaccharide (Sigma-Aldrich) at the cell counts and conditions previously described for the IFN- $\beta$ expression. Each condition was replicated in triplicate. Cells were harvested $24 \mathrm{~h}$ post-transfection, and RNA was extracted by Aurum Total RNA Mini Kit. RNA reverse transcription and RT-PCR were carried out using the same method as IFN- $\beta$ expression. The IL-6 primer [33] used for RT-PCR is listed in Supplementary Table 1.

\section{Microscale thermophoresis}

Microscale thermophoresis (MST) experiments were performed, using a NanoTemper Monolith NT.155. Briefly, $50 \mathrm{nM}$ FAM labeled 100 bp dsDNA (sequence in Supplementary Table 1) in HEPES buffer (10 mM HEPES, $140 \mathrm{mM} \mathrm{NaCl}$ and $5 \mathrm{mM} \mathrm{MgCl}_{2} ; \mathrm{pH}=7.5$ ) was incubated with a dilution series of suramin, diminazene aceturate or propidium iodide. Samples were loaded into MST Premium Coated Monolith NT.115 Capillaries. MST was performed using 20\% Blue Excitation Power and Medium MST power. The On Time 1.5 s Evaluation Strategy was used by the NT Analysis Software to generate the MST response. Samples were prepared in triplicate.

\section{Fluorescent DNA displacement assay}

100 -bp annealed dsDNA $(0.1 \mu \mathrm{M}$ for proflavin assay or $0.2 \mu \mathrm{M}$ for DAPI assay) was prepared in Tris- $\mathrm{HCl}$ buffer (20 mM Tris, $100 \mathrm{mM} \mathrm{KCl}, \mathrm{pH}$ 7.2). Two micromolar proflavine or DAPI was added and the mixture was incubated for 5 min. Emission measurement was taken after addition of each indicated concentration of suramin followed by an equilibration time for $5 \mathrm{~min}$. The fluorescence intensity (F) of DAPI (Ex: $340 \mathrm{~nm}, \mathrm{Em}: 460 \mathrm{~nm}$ ) and proflavine 
(Ex: $444 \mathrm{~nm}, \mathrm{Em}: 510 \mathrm{~nm}$ ) was converted into percentage of displacement (PD) by using the following equation.

$$
\text { DAPI }: P D=100-\left[\left(F_{s} / F_{0}\right) \times 100\right]
$$

$\left(\mathrm{F}_{0}=\right.$ fluorescence intensity of DNA-DAPI complex in the absence of suramin; $\mathrm{F}_{\mathrm{s}}=$ fluorescence intensity in the presence of suramin).

$$
\text { Proflavine }: \mathrm{PD}=\left(\mathrm{F}_{\mathrm{s}}-\mathrm{F}_{0}\right) /\left(\mathrm{F}_{\max }-\mathrm{F}_{0}\right)^{\infty} \times 100
$$

$\left(\mathrm{F}_{0}=\right.$ fluorescence intensity of DNA-proflavine complex in the absence of suramin; $\mathrm{F}_{\mathrm{s}}=$ fluorescence intensity in the presence of suramin; $F_{\max }=$ fluorescence intensity of proflavine in the absence of DNA).

\section{Results}

\section{Discovery of suramin as cGAS inhibitor from compound library}

To identify potential cGAS inhibitors we screened a small library of 268 compounds to evaluate inhibition of human cGAS activity via HPLC analysis of the reaction mixture (after $2 \mathrm{~h}$ of incubating cGAS with ATP, GTP and the putative inhibitors). Library compounds were selected based on structural similarities to ATP and the potential for inhibition of dsDNA binding to cGAS [27]. For the initial screening (using $3 \mu \mathrm{M}$ cGAS, $200 \mu \mathrm{M}$ ATP/GTP and $20 \mu \mathrm{M}$ of putative inhibitors), a cut-off of $30 \%$ enzymatic inhibition was considered significant and suramin was identified as an inhibitor of cGAS activity (Figure 2A).

A panel of suramin analogs (Figure 2A) [34] was then examined to evaluate the suramin structure-activity relationship, however, no inhibition activity was observed. Although the HPLC analysis of the cGAS reaction mixture had indicated inhibition by suramin (Figure 2B), we proceeded to use a second assay to confirm the inhibition of cGAS by suramin by using radioactive $\alpha-{ }^{32} \mathrm{P}$-ATP as a substrate for cGAS and visualization using TLC with autoradiography imaging to analyze the reaction mixture (Figure 2C). In line with the HPLC results, the TLC analysis also indicated that the inhibition of cGAMP synthesis by suramin was dose-dependent.

\section{Suramin facilitated displacement of DNA from hcGAS}

DNA binding induces conformational changes and crosslinks cGAS dimers to restrict the structural flexibility of cGAS and stabilize the active conformation, which catalyzes the formation of $2^{\prime}, 5^{\prime}$-cGAMP [16]. cGAS activity is known to be stimulated by DNA of varied sequences, including poly(deoxyadenosine-deoxythymidine), poly(deoxyguanosine-deoxycytidine) and 45-base pair immune stimulatory DNA [1]. Inhibitors of cGAMP synthesis can either inhibit dinucleotide synthesis by binding to the active site of cGAS [24,25] or the DNA [23]. An alternative mode of inhibition, which has yet to be demonstrated, is for an inhibitor to compete with the duplex DNA for cGAS binding. This could occur via inhibitor binding directly to the DNA binding site or binding to an alternative site, which results in a conformational change to reduce cGAS affinity for DNA. Suramin is polyanionic and is not a potent DNA binder, vide infra, so we rationalized that the inhibition of cGAS by suramin could be via the displacement of DNA from cGAS. In other words, suramin could act as a DNA mimic but unable to activate cGAS for cGAMP synthesis. To investigate this possibility, an EMSA was performed using FAM labeled DNA to assess the effect of suramin on DNA binding to human cGAS (Figure 3). The suitability of 100-bp dsDNA in a cGAS inhibition assay was previously demonstrated, which guided our choice for its use in this experiment [23]. cGAS addition to the DNA resulted in a sharp decrease in free $100 \mathrm{bp}$ DNA (Figure 3, lane 2). Addition of QC, a known cGAS inhibitor, which perturbs cGAS/dsDNA binding, resulted in recovery of the 100-bp DNA band (Figure 3, lane 7). Addition of increasing concentration of suramin resulted in an increase in the 100-bp dsDNA band density in a dose-dependent manner (Figure 3, lanes 3-6). This indicates that suramin could inhibit cGAS activity in a dose-dependent manner through disrupting dsDNA/cGAS binding. Suramin was able to disrupt dsDNA/cGAS binding even when DNA and cGAS were preincubated to form the DNA/cGAS complex prior to suramin addition as was the case here.

To ensure that the displacement of DNA observed was not due to an interaction with DNA itself, which is the mode of cGAS inhibition by QC [23], MST experiment was performed in which the response of the FAM labeled dsDNA was measured in the presence of suramin, DNA minor groove binder diminazine aceturate or 
(A)

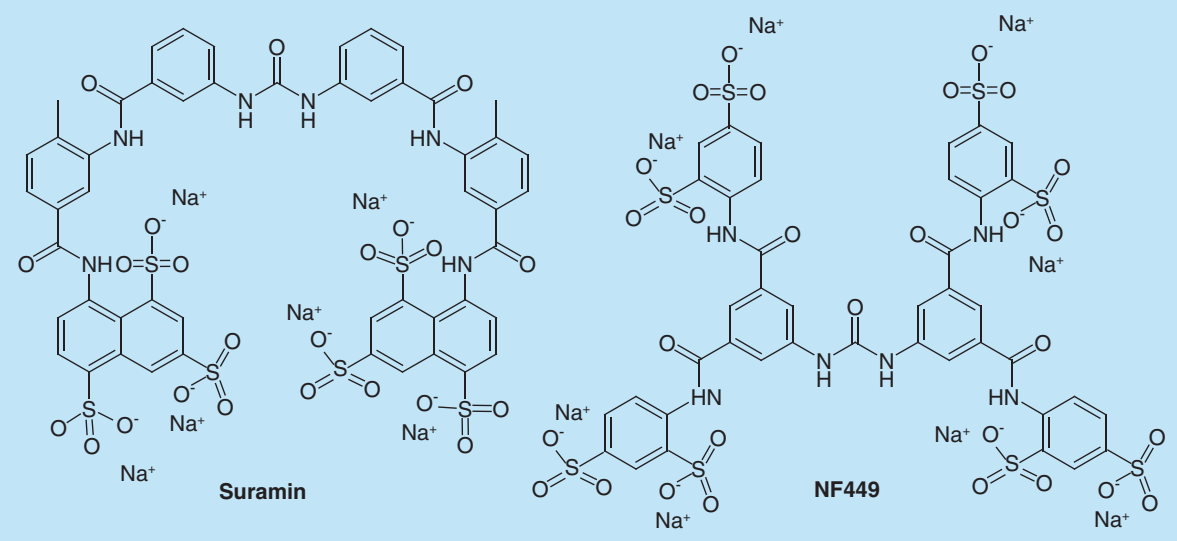<smiles>CS(=O)(=O)Nc1ccc(S(=O)(=O)Nc2ccc(S(=O)(=O)O[Na])cc2)cc1</smiles>

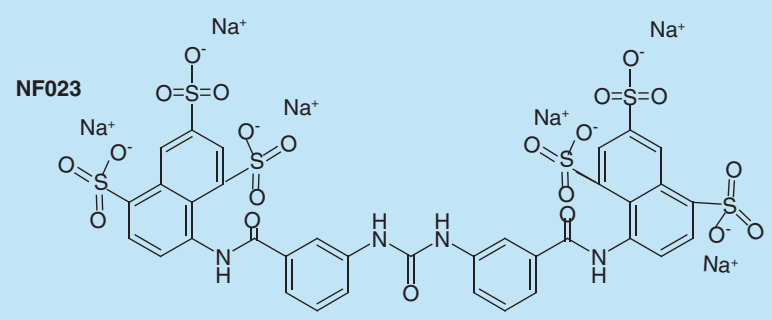<smiles>O=C(Nc1cccc(C(=O)Nc2ccc(S(=O)(=O)O[Na])cc2)c1C(=O)Nc1ccc(S(=O)(=O)[O-])cc1)Nc1cccc(C(=O)Nc2ccc(S(=O)(=O)O[Na])cc2)c1C(=O)Nc1ccc(S(=O)(=O)O[Na])cc1</smiles>

(B)

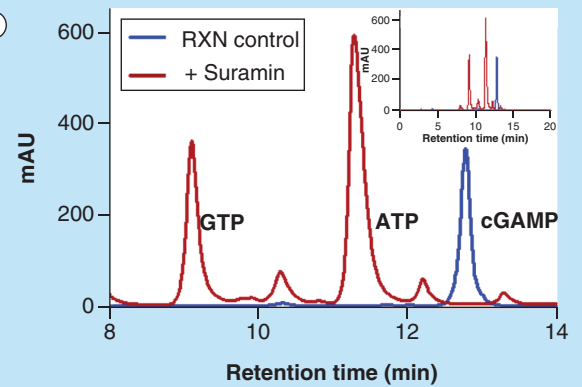

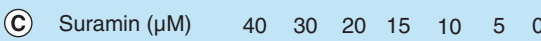

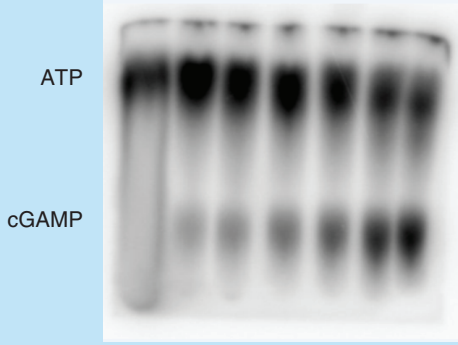

Figure 2. Screening and identification of suramin as potential inhibitor of cGAMP synthesis by cGAS. (A) Structures of suramin and analogs. (B) HPLC analysis of cGAS synthesis of cGAMP in the absence (blue) and presence (red) of $20 \mu \mathrm{M}$ suramin. Inset shows retention time 0-20 min. (C) TLC of cGAS inhibition experiments, using indicated concentrations of suramin.

DNA intercalator propidium iodide. The data is shown in the Supplementary Data (Supplementary Figure 3) and, as expected for a polyanionic species, suramin does not show evidence of an interaction with DNA, even at concentrations of suramin as high as $5 \mathrm{mM}$. In addition to the MST experiments, several indirect displacement experiments (using fluorogenic DNA intercalators or minor grove binders) indicated that suramin does not bind to DNA (Supplementary Figure 4). DAPI, a fluorescent minor groove binding probe for DNA, was used to stain dsDNA. Displacement of DAPI by a minor groove binder such as diminazene will result in a decrease in the fluorescence of DAPI. Diminazene was found to displace $50 \%$ of DAPI at a concentration of $2 \mu \mathrm{M}$ while suramin was found to exhibit only approximately $26 \%$ displacement of DAPI at concentrations as high as $20 \mu \mathrm{M}$ suramin. This low level of DAPI displacement by suramin could be due to the interactions of anionic suramin with DAPI. No significant displacement of DNA intercalator proflavine was observed upon addition of up to $50 \mu \mathrm{M}$ of suramin, contrasted to the obvious displacement by propidium iodide under the same conditions. These results support the notion that DNA and suramin do not significantly interact. 
Figure 3. Inhibition on DNA-cGAS binding by suramin was investigated using electrophoretic mobility shift assay. Fluorescently labeled dsDNA $(1 \mu \mathrm{M})$ and cGAS $(5 \mu \mathrm{M})$ were incubated for $1 \mathrm{~h}$ at room temperature. Suramin was then added for an additional $2 \mathrm{~h}$ and subjected to electrophoresis. Lane 1: $1 \mu \mathrm{M}$ fluorescently labeled dsDNA. Lane 2-6: Fluorescently labeled dsDNA and cGAS with 0, 1, 10, 100 and $200 \mu \mathrm{M}$ suramin. Lane 7: positive control - QC $(250 \mu \mathrm{M})$.

QC: Quinacrine.

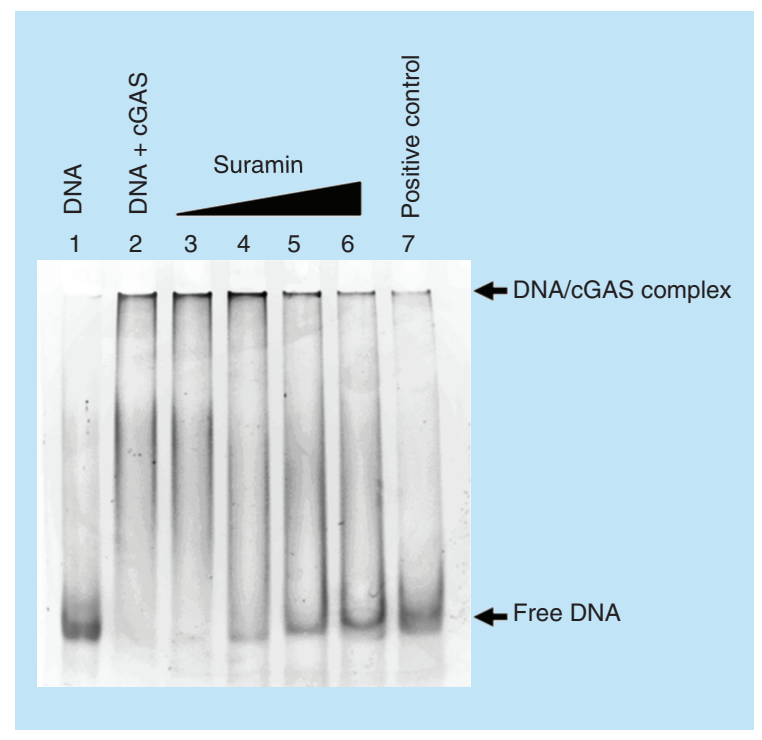

\section{Functional modulation of hcGAS activity by suramin}

Having observed in vitro that suramin inhibits cGAS (Figure 2B \& C) and also inhibits dsDNA binding to cGAS (Figure 3), we sought to evaluate the activity of suramin in suppressing dsDNA-dependent activation of cGAS and therefore downregulation of type I IFN genes in cells (using THP1-Dual cells [25]). Upon IRF pathway stimulation with $2^{\prime} 3^{\prime}$-cGAMP in THP1-Dual cells, a luciferase reporter protein, which is readily measureable in plate format via a commercially available kit, is produced [35]. As expected, when THP1-Dual cells were stimulated with dsDNA to produce cGAMP, the reporter protein indicated that the IRF pathway was stimulated and therefore IFN- $\beta$ was expressed. When increasing concentrations of suramin were added to the stimulated THP1-Dual cells, the level of IFN- $\beta$ expression decreased (Figure 4B). At $5 \mu \mathrm{M}$ of suramin, the level of IFN- $\beta$ expression was similar to that seen in unstimulated cells, indicating that the suramin could suppress cGAMP production in the cells. To eliminate the possibility that suramin exhibits toxicity to cells, which reduced the IFN- $\beta$ production, we investigated the toxicity of suramin against the THP1-Dual cells and no significant change of cell viability was observed in the presence of $5 \mu \mathrm{M}$ suramin, which is the maximum dosage used throughout this study (Figure 4A). This result eliminates the possibility that suramin may be exhibiting toxicity to the cells resulting in a reduction of the IFN- $\beta$ production.

If suramin affects IFN- $\beta$ protein expression levels via inhibition of cGAMP synthesis, the levels of IFN- $\beta$ mRNA would be expected to show a decrease. To test this hypothesis, we transfected the THP1-Dual cells with dsDNA and investigated the mRNA expression of IFN- $\beta$. As observed in Figure 4C, type I IFN response was enhanced significantly upon transfection of dsDNA while the response was inhibited in the dose-dependent manner of suramin. It indicates the ability of suramin to inhibit dsDNA-dependent cGAS-mediated signaling in cellulo.

To demonstrate that suramin could enter the cell and attenuate cGAS activity, but not simply affect DNA transfection efficiency, we incubated the transfection cocktail (DNA/Lipofectamine complex) with cells for 30 min, then washed the cell and cultured the cell in fresh media with and without suramin for $24 \mathrm{~h}$. The rationale for the aforementioned protocol is that the DNA will enter the cells in the first $30 \mathrm{~min}$ and the remaining DNA will be washed out before suramin was added. Preliminary investigations had shown that the IFN- $\beta$ mRNA level as well as the level of the luciferase reporter in THP1-Dual cells increased upon a brief DNA transfection time of $30 \mathrm{~min}$ (although $24 \mathrm{~h}$ transfection time improved response). Using this 'washout' protocol, we observed that the expression of IFN- $\beta$ (the gene product of cGAS mediated signaling) as well as the level of the luciferase reporter (determined via the enzymatic activity of the reporter) were increased upon brief DNA transfection (30 min) and that suramin (added after the DNA transfection step) could still reduce the IFN- $\beta$ expression (Figure 5A) and the level of the luciferase reporter (Figure 5B). Additionally we also determined that suramin did not affect the transfection of GFP plasmid into HEK293 cells (Supplementary Figure 2). These results demonstrate that the effect of suramin on IFN- $\beta$ expression is not via the disruption of DNA transfection but rather it is due to the ability of suramin to enter the cells and attenuate the activity of cGAS. 
(A)

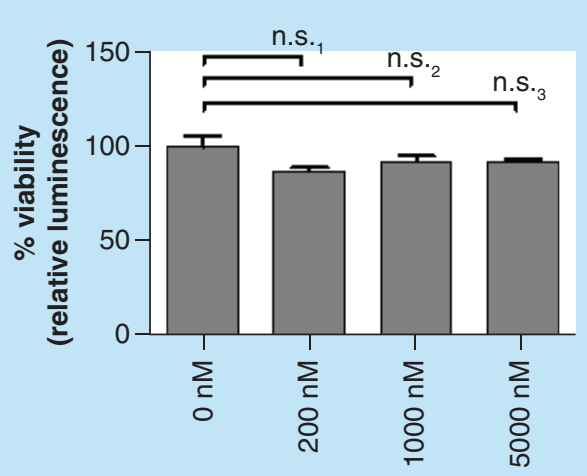

[Suramin]
(B)

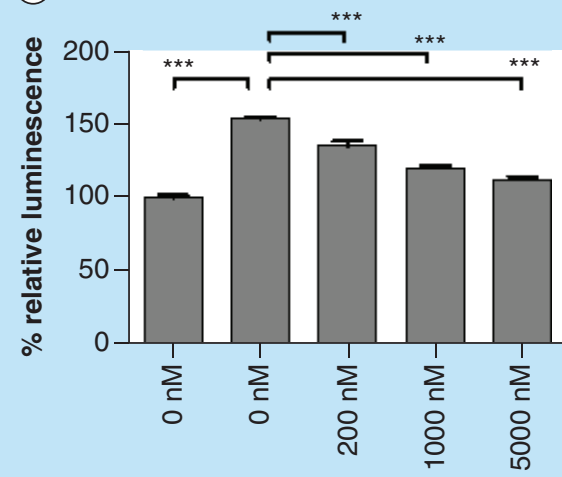

[Suramin]

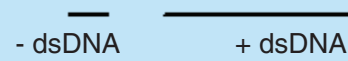

(C)

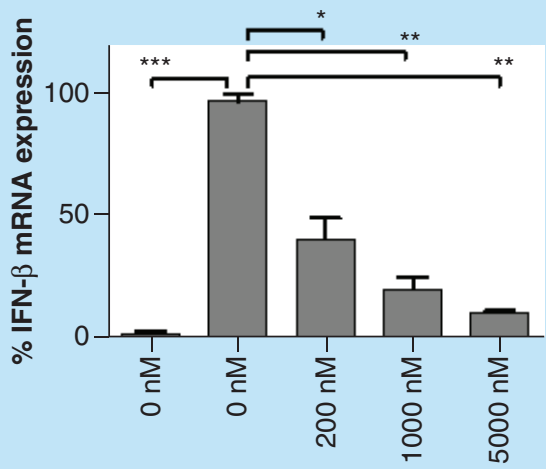

[Suramin]

- dsDNA +dsDNA

Figure 4. Suramin decreases the expression of the dsDNA-stimulated IRF pathway at concentrations that do not exhibit cell lethality. (A) Viability of THP1-Dual ${ }^{\text {TM }}$ cells in the presence of Suramin. Suramin does not affect the viability of THP1-Dual cells up to a concentration of 5000 nM. (n.s.1, $p=0.0845$, not significantly different; n.s.2, p = 0.2696, not significantly different; n.s.3, $\mathrm{p}=0.2377$, not significantly different). (B) Change in luciferase reporter expression (luminescence signal) in response to IRF pathway stimulation indicating IFN- $\beta$ expression in THP1-Dual cells upon transfection of dsDNA in the presence and absence of suramin. (C) Relative mRNA level of IFN- $\beta$ in THP1-Dual cells upon transfection of dsDNA in the presence and absence of suramin. Error bars shown as standard error of the mean from three independent trail.

${ }^{*} \mathrm{p}<0.05 ; * * \mathrm{p}<0.01 ; * * \mathrm{p}<0.001$.

n.s: Not significant.

To demonstrate that suramin inhibits cGAS activity but not the downstream target of cGAS mediated signaling pathway, we used THP1-Dual KO-cGAS cells that are deficient in the cGAS protein and stimulated them with dsDNA or cGAMP. When these cells are exposed to cGAMP, the STING pathway is activated but suramin was not found to significantly decrease the IFN stimulation (Figure 6). This emphasizes that suramin selectively inhibits the cGAS activity but not the downstream target of cGAS mediated signaling.

We also examined the ability of suramin to inhibit other innate immune signaling pathways such as TLR2/TLR1 and TLR4. We performed RT-PCR to investigate the expression level of IL-6, which is a proinflammatory cytokine triggered by toll like receptors (TLRs). Suramin is known to have anti-inflammatory activity upon stimulation of immune cells by other stimuli [36]. To test whether in addition to inhibiting the DNA sensing pathway, suramin also affected additional signaling pathways that are activated by other pathogen-associated molecular patterns, we determined the level of IL- 6 mRNA following stimulation by other non-DNA stimuli (lipopolysaccharide [LPS], Pam3CSK4 lipopeptide and Poly(I:C)). Upon stimulation of the cognate ligands, Pam3CSK4 (Tlr2/1) and 
(A)

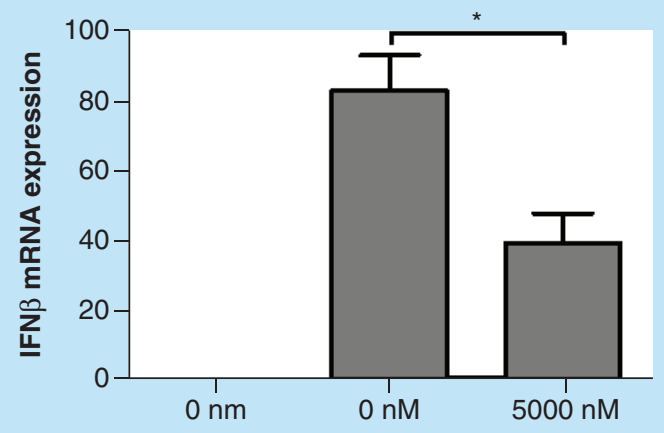

[Suramin]
(B)

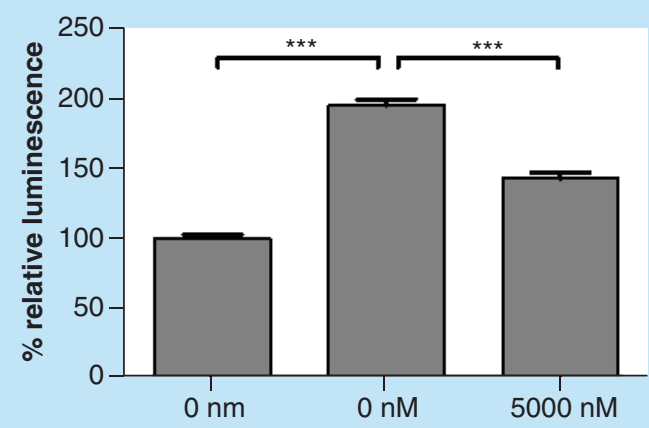

[Suramin]

- dsDNA

$$
+ \text { dsDNA }
$$

$$
+ \text { dsDNA }
$$

Figure 5. Suramin-mediated inhibition of IFN- $\beta$ stimulation is not the result of DNA transfection disruption. The relative mRNA level normalized to GAPDH (A) and the relative luminescence from luciferase reporter (B) indicate the level of IFN- $\beta$ expression of THP1-Dual ${ }^{T M}$ cells upon 30 min pretransfection of dsDNA and $23.5 \mathrm{~h}$ of incubation of suramin. Error bars shown as standard error of the mean from three independent trails. ${ }^{*} \mathrm{p}<0.05 ; * * * p<0.001$.

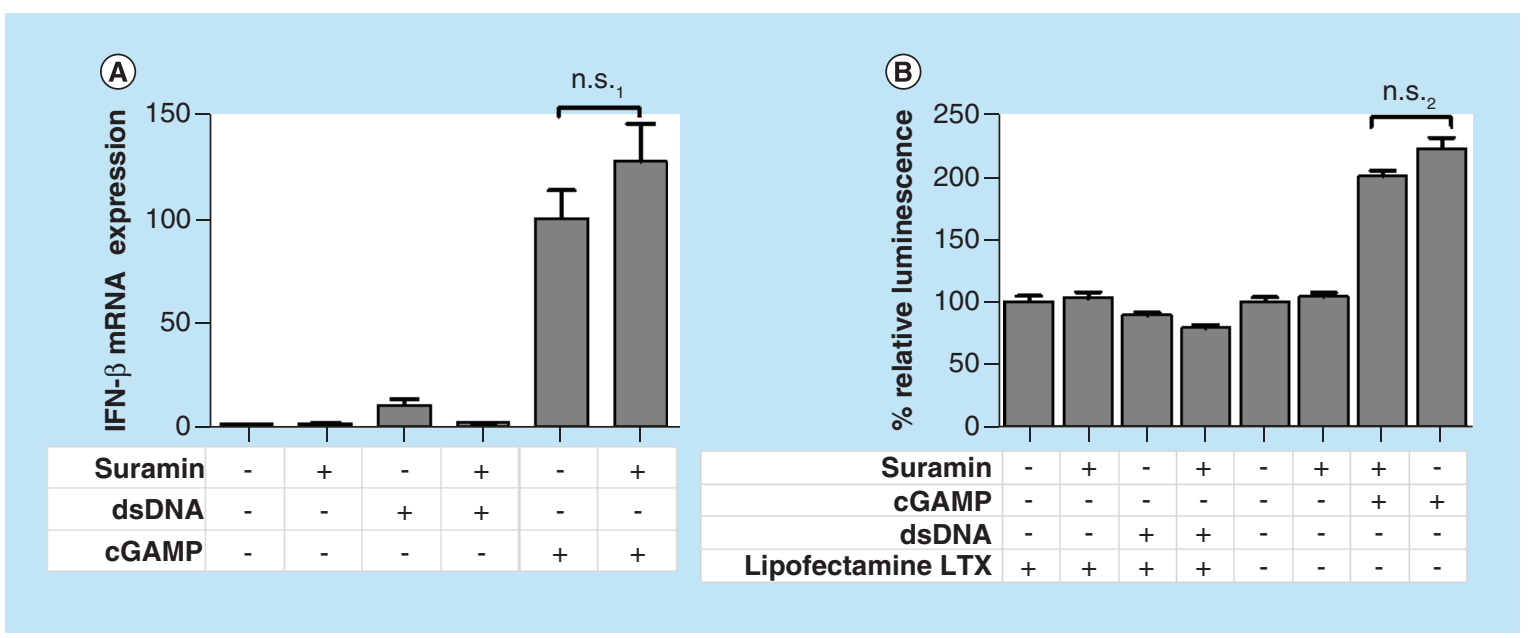

Figure 6. cGAMP rescues IFN- $\beta$ stimulation in the presence of suramin. (A) Relative expression of IFN- $\beta$ mRNA (normalized to GAPDH) in THP1-Dual ${ }^{T M} \mathrm{KO}-\mathrm{cGAS}$ cells exposed to dsDNA or cGAMP and simultaneously treated with $5 \mu \mathrm{M}$ suramin. (n.S.1, $\mathrm{p}=0.2853$, not significantly different) (B) Change in expression of luciferase reporter protein in response to type 1 IFN stimulation indicating IFN- $\beta$ expression in THP1-Dual KO-cGAS cells. CGAS produces cGAMP which activates the STING pathway. KO-cGAS activity may be rescued by the addition of cGAMP. THP1-Dual KO-cGAS cells are insensitive to cGAS inhibition by suramin. Error bars shown as standard error of the mean from three independent trails. (n.s.2, $p=0.0809$, not significantly different).

n.s: Not significant.

lipopolysaccharide (Tlr4), an increase of IL-6 expression was recorded, while no significant change was observed in the presence of suramin (Figure 7A \& B). In the case of Poly(I:C), the addition of $5000 \mathrm{nM}$ suramin resulted in a suppression of IL-6 expression (Figure 7C).

\section{Discussion}

cGAS is indispensable for IFN- $\beta$ induction by cytosolic DNA, as determined by transfection experiments of DNA into the lung fibroblasts of WT and $\mathrm{cGas}^{+/-}$mice resulting in robust production of IFN- $\beta$, while induction was 


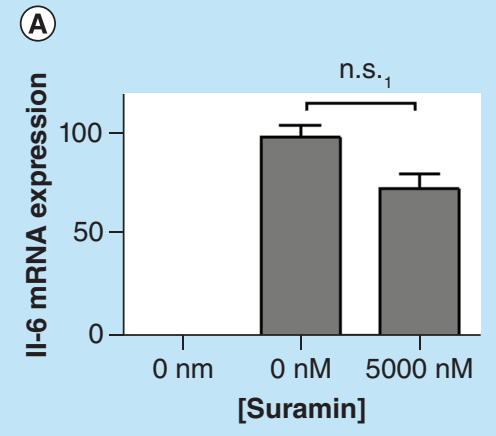

Pam3CSK4
(B)

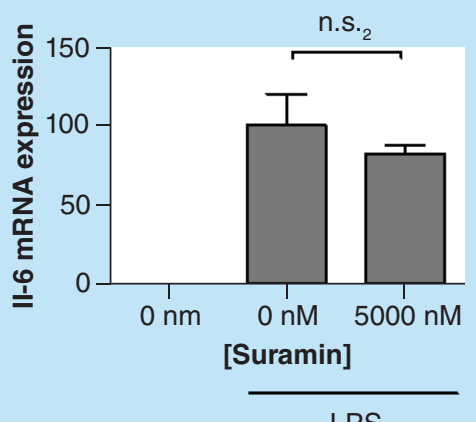

LPS
(C)

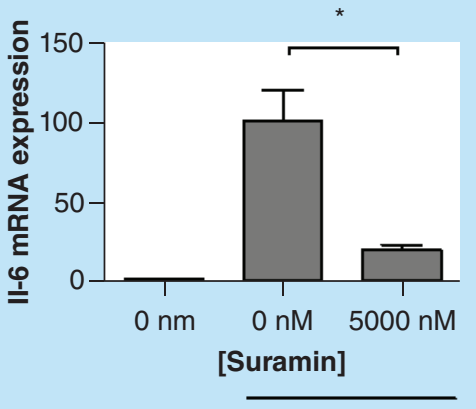

Poly (l:C)

Figure 7. Suramin does not significantly decrease all signaling pathways examined that are activated by non-DNA pathogen-associated molecular patterns. Relative expression of IL-6 mRNA (normalized to GAPDH) in THP1-Dual ${ }^{\mathrm{TM}}$ cells exposed to (A) Pam3CSK4, (B) LPS and (C) Poly(I:C) simultaneously treated with $5 \mu \mathrm{M}$ suramin. (n.s.1, p = 0.06, not significantly different; n.s.2, $p=0.42$, not significantly different) Error bars shown as standard error of the mean from three independent trails.

${ }^{*} \mathrm{p}<0.05$.

LPS: Lipopolysaccharide; n.s: Not significant.

completely abolished in a $\mathrm{cGas}^{-/-}$mouse strain [37]. Though the pathway is essential for antiviral immune response, it must be tightly regulated to avoid an inappropriate response against self DNA, which may be present in cytoplasm, as chronic activation is implicated in autoimmune disease [5]. TREX1 is an exonuclease that degrades DNA in the cytoplasm [14]. Gray et al. utilized TREX1-deficient mice, which developed multi-organ inflammation, including severe inflammatory myocarditis that is dependent on type I IFNs and STING, and found that when cGAS was knocked out, the mice showed no signs of inflammation [5]. Their study demonstrated that cGAS is a key driver of autoimmune disease and suggested that cGAS inhibitors may be useful therapeutics for AGS patients with TREX1 mutations [5]. Gao et al. also suggested that inhibition of cGAS may be an effective therapy for autoimmune diseases such as AGS and systemic lupus erythematosus [6].

An $e t$ al. performed in silico screening of drug libraries which identified several antimalarial drugs that were predicted to interact with a cGAS•dsDNA complex [23]. Hydroxychloroquine and QC were found to disrupt the cGAS•dsDNA complex as determined by EMSA [23]. Dose-titration experiments with recombinant cGAS were performed and cGAMP production was quantified using TLC to determine the $\mathrm{IC}_{50}$ for inhibition of cGAMP production with QC and ACMA revealed as the most potent inhibitors of cGAMP production examined (low $\mu \mathrm{M}$ range) [23]. An et al. also tracked the expression of IFN- $\beta$ in THP1 cells in response to DNA transfection and found $\mathrm{QC}$ and ACMA to have single digit micromolar $\mathrm{IC}_{50}$ values for inhibition of IFN- $\beta$ expression [23].

\section{Suramin inhibits CGAS \& has been shown to enter cells by an uncharacterized mechanism}

Our screening for inhibitors of cGAS identified suramin. This screening hit was exciting because repurposing known drugs for novel indications has benefits including known toxicological profiles and a scaffold that is known to be compatible with dosing cellular targets, all of which may expedite translation into a new therapeutic. In addition to being an approved drug for trypanosomiases, suramin has also been investigated in the clinic for a few disease states (autism [clinical trials number NCT02508259], breast cancer [clinical trials number NCT00054028]). Suramin, being polyanionic is expected to have poor cellular permeation properties but interestingly suramin has been shown to cross into cells to affect signaling processes [38]. Using autoradiographic techniques, Baghdiguian et al. showed that tritiated suramin enters colon (HT-29-D4) cells and therefore put to rest any doubts regarding suramin's ability to enter cells [39]. Additionally, several studies have shown that suramin is able to inhibit various cancer cell lines, presumably after entering those cells to affect various intracellular proteins [40,41]. Suramin has been demonstrated to accumulate in mammalian cell lines in the acidic intracellular compartments (trans-Golgi complex; exocytic vesicles) at concentrations in excess of $150 \mu \mathrm{M}$ [2]. The mechanism of suramin uptake is not well understood but appears to occur via receptor-mediated endocytosis by a non-LDL-mediated route in trypanosome cells [1]. 
Drugs that are unable to diffuse freely across membranes must engage in transport through a channel, transporter or the flagellar pocket in trypanosome cells [1]. The identity of the receptor on human cells that bind to suramin to facilitate uptake remains uncharacterized, though once internalized the charge of suramin may prevent an easy escape from the cell, which allows internal cellular concentrations to exceed that of the extracellular environment [1].

\section{Suramin disrupts dsDNA/cGAS binding \& downregulates the type-I IFN response}

EMSA experimental results indicated that suramin disrupts dsDNA/cGAS binding. Suramin was able to disrupt dsDNA/cGAS binding even when DNA and cGAS were preincubated to form the DNA/cGAS complex prior to suramin addition and this disruption is a potential mechanism for the inhibition of dsDNA stimulated cGAS activity. We saw that suramin inhibited the expression of INF- $\beta$, likely by inhibition of cGAS, which limits cGAMP production and therefore activation of the STING pathway. This could be due to either binding to the active site of cGAS, or more likely by interfering with the ability of cGAS to bind DNA, with the latter mode being suggested by EMSA.

Having shown that suramin is able to disrupt the interaction of DNA with cGAS in vitro, we undertook in cellulo studies to examine the expression of IFN- $\beta$. IFN- $\beta$ expression is stimulated by STING, which also controls proinflammatory cytokine production and chronic activation is a key factor in development of autoimmune diseases, such as rheumatoid arthritis, inflammatory bowel disease and others [42]. STING is stimulated by $2^{\prime} 3^{\prime}$-cGAMP, which is produced by cGAS when stimulated with dsDNA. Transfection experiments demonstrated a reduction in IFN- $\beta$ expression in response to HT-DNA stimulation in the presence of increasing concentrations of suramin. As expected, the expression of IFN- $\beta$ mRNA followed a similar trend to the protein expression experiment (determined via the luciferase reporter), with a decrease in STING mediated mRNA expression in response to the lower levels of cGAMP present due to cGAS inhibition. Experiments using a cGAS knockout cell line clearly illustrated the recovery of the STING pathway upon activation with cGAMP, even in the presence of high suramin concentrations $(5 \mu \mathrm{M})$ (Figure 6B).

Pam3CSK4 activates TLR2 [43], which leads to the recruitment of MyD88 and the IRAKs [8]. IRAK4 phosphorylates IRAK1 [8]. Phosphorylated IRAK1 activates TRAF6, which becomes ubiquitinated and triggers the

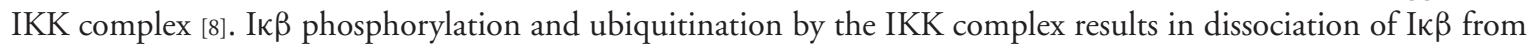
$\mathrm{NF}-\kappa \beta$ [8]. NF- $\kappa \beta$ is then able to cross into the nucleus and activate the IL-6 producing gene [8]. LPS interacts with TLR4, which in the classical pathway phosphorylates Iк $\beta$, resulting in its dissociation from NF-к $\beta$, which allows NF- $\kappa \beta$ to cross the nuclear membrane and activate the IL-6 producing gene [7]. The lack of inhibition of IL-6 expression upon stimulation by LPS and Pam3CSK4 by suramin (Figure 7A \& B) indicates that the effect of suramin on cell signaling is not promiscuous.

dsRNAs induce type-I IFN responses differently, depending on the source of the RNA used for experiments, be it endogenous, in vitro synthesized, synthetic (such as Poly(I:C)), or of viral origin, and mammalian cells detect RNA substrates using a multitude of pathways to elicit the type-I IFN response [44]. In response to dsRNA, PKR

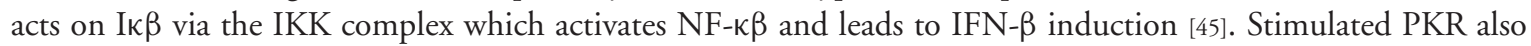
phosphorylates eIF2 $\alpha$, which then binds eIF2B and this complex inhibits translation initiation by the ribosomal complex that confers an antiviral state [44]. Other sensors for dsRNA have been discovered, including TLR3, with responds to viral dsRNA. Synthetic Poly(I:C) engages the TLR3 signaling pathway to activate a type-I IFN response

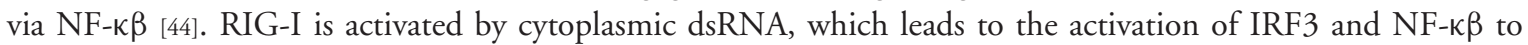
elicit the type-I IFN response [44]. MDA5 is also a key mediator of virally induced type-I IFN signaling, which

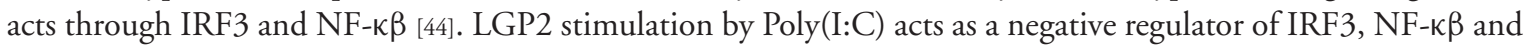
IFN- $\beta$ induction, potentially through the inhibition of RIB-I and MDA5 induction by the same substrate [46]. The effects of duplex RNA on immune response is further complicated because type-I IFN response is involved in the induction of cGAS [47]. The increased expression has the potential to increase activity of the STING pathway if DNA is present in the cytoplasm, and result in type-I IFN signaling [1]. Clearly the impact of Poly(I:C) stimulation has consequences on multiple pathways and cellular data would be very convoluted by the interplay of pathways. Despite these complications we still evaluated how suramin affected the effects of duplex RNA (Poly(I:C)).

\section{Suramin may act as a nucleic acid mimic}

The inhibition of Poly(I:C)-stimulated IL-6 expression by suramin, a polyanionic compound, is interesting and it could imply that suramin is capable of mimicking nucleic acids and competes with DNA or RNA for binding to positive patches found in DNA or RNA binding proteins. Perhaps the anionic sulfonates act as phosphate mimics. 
This is an interesting proposal and in general could impact the design of molecules to inhibit other nucleic acid binding proteins. In fact others have also observed that suramin can bind to positive patches on other proteins. For example, the acidic C-terminal tail of Cdc34, ubiquitin-conjugating enzyme E2 R1, binds to a basic cleft of Cullin-Ring ubiquitin ligases, such as CUL1, via electrostatic interactions [34]. Wu et al. showed that suramin can interact with the basic patch cleft of CUL1 (a component of SCF E3 ubiquitin ligase complex) and prevent the binding of Cdc34 [34]. Figure 8 shows an electrostatic surface of DNA, RNA and several proteins (AIM2, CUL1 RIG-1 and cGAS) with electrostatic surfaces indicating where the nucleic acid or suramin is found to bind. A common theme of this figure is the overwhelmingly positive character of these binding regions, which interact readily with negatively charged substrates such as nucleic acids.

Recently, suramin was found to bind the positive region of fivefold axis of the EV-A71 capsid and interfere with capsid binding of attachment factors (heparin sulfate glycosaminoglycans) required for virus attachment and entry into a host cell and thereby inhibited multiple enterovirus A [51]. Mutations to the capsid greatly reduced suramin binding and also reduced binding of heparin, while mutations to nearby residues that restored the positive character facilitated heparin and suramin binding once more [51].

Additional evidence for suramin as a binder of positive patches on proteins comes from the binding of suramin to Moloney murine sarcoma virus reverse transcriptase at the primer/template binding site [52]. Suramin interacts with the template-primer binding site in a competitive manner, and was described by the author as belonging to a new class of reverse transcription inhibitors that are not primer or template DNA analogs, but interact with the template-primer region of DNA polymerase [52]. Suramin is known to have a protective effect in ATH8 cells against the cytopathic effect of human T-cell lymphotropic virus type III/lymphadenopathy-associated virus (HTLV-III/LAV) reverse transcriptase at $50 \mu \mathrm{g} / \mathrm{ml}$, a dose that did not exhibit toxicity to uninfected cells [53]. The viral core (gag) p24 protein expression is completely suppressed at this concentration, which suggests that virus replicative cycle inhibition is the most likely cause of the protective effect [53,54]. The uptake of suramin by endocytosis for release into the cytoplasm would give suramin the opportunity to bind the viral reverse transcriptase before RNA is integrated into viral dsDNA for transport to the nucleus where cellular DNA polymerases would be sequestered [53].

It is therefore tantalizing to propose that suramin or other polysulfonated aromatics are general motifs to interrupt protein-nucleic acids or protein-protein interactions that occur via extensive electrostatic interactions. We, however, note that the immune activation by duplex RNA is complex and could involve regulation of cGAS, which is a DNA binder. It is therefore premature to suggest that suramin will also interrupt RNA-RIG-1 interactions without more data, which is beyond the scope of the current report. Others had also noted the inhibition of Poly(I:C)-stimulated induction of IL-6 expression by antimalarial drugs, also cGAS inhibitors, in THP-1 cells [23]. Plausibly, these antimalarial drugs, which bind to nucleic acids, interrupted the Poly(I:C)-stimulated induction of IL-6 by directly interacting with the Poly(I:C) or via other ill-defined mechanism(s). Suramin, on the other hand, does not strongly bind to nucleic acids (Supplementary Figures S4 \& S5) so it is unlikely that the reduction of the IL-6 mRNA induction (via Poly(I:C) stimulation) is via binding to RNA. More detailed future work (beyond the scope of this report) is needed to clarify if suramin is indeed a general inhibitor of nucleic acid binding proteins.

\section{Conclusion}

Using HPLC analysis of cGAS reaction mixture, we uncovered that suramin is a potent inhibitor of cGAS. This was confirmed by using a radiolabelled $\alpha{ }^{3}{ }^{32} \mathrm{P}-\mathrm{ATP}$ substrate for cGAS followed by TLC and autoradiography imaging. Both results indicated that the inhibition of cGAMP synthesis by suramin was dose-dependent. Reduced activity of TREX1 can lead to increased IFN- $\beta$ production [55]. Persistent activation of cGAS by cytosolic dsDNA will lead to unregulated activation of STING by $3^{\prime}, 5^{\prime}$-cGAMP, which can result in chronic inflammation. Inhibition of cGAS activity could be a potential therapeutic strategy for diseases caused by reduced TREX1 activity, such as lupus [56]. Here, we have identified suramin as a cGAS inhibitor with potential application in treating chronic inflammation due to unregulated cGAS-STING pathway activation. In addition to cGAS playing a major role in bacterial pathogen clearance, cGAS has also emerged as important player in macular degeneration [57], cellular senescence [58-60], inflammatory response to malaria infection [61], myocardial infarction-related inflammation [62] and macrophage transformation [63] among others. Inhibitors of cGAS-mediated production of cGAMP could have extensive utility in medicine. 
(A)

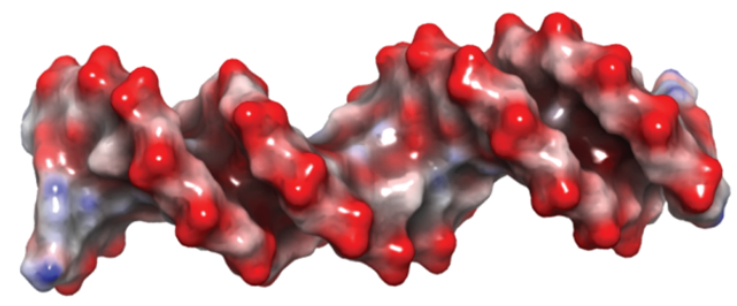

(C)

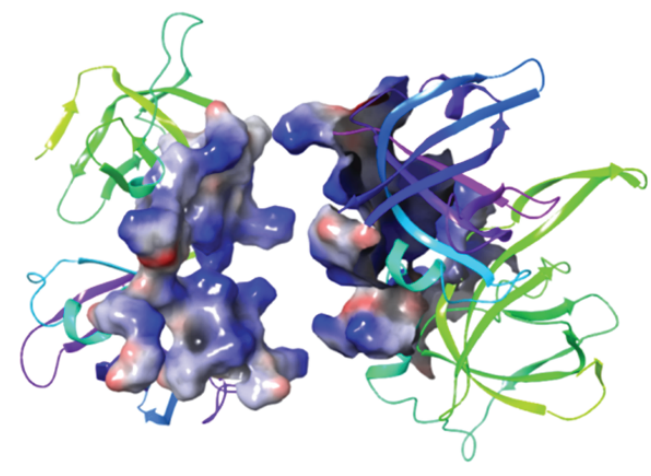

(E)

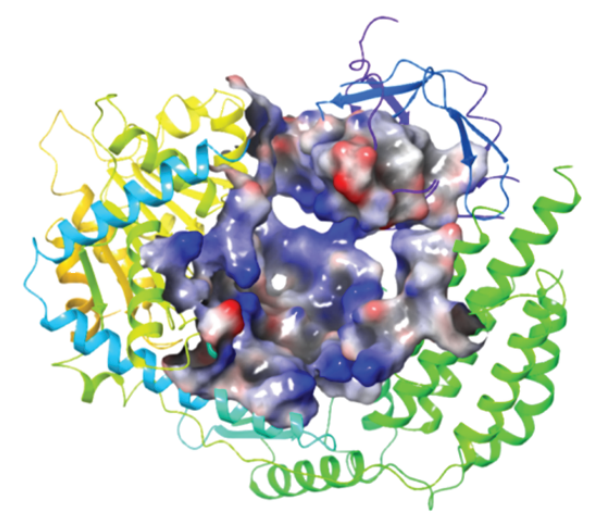

(B)

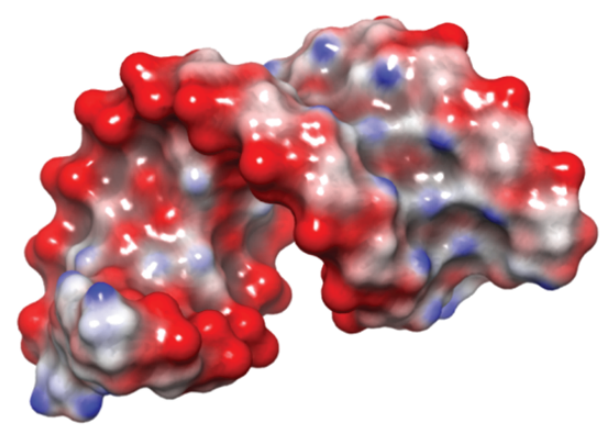

(D)

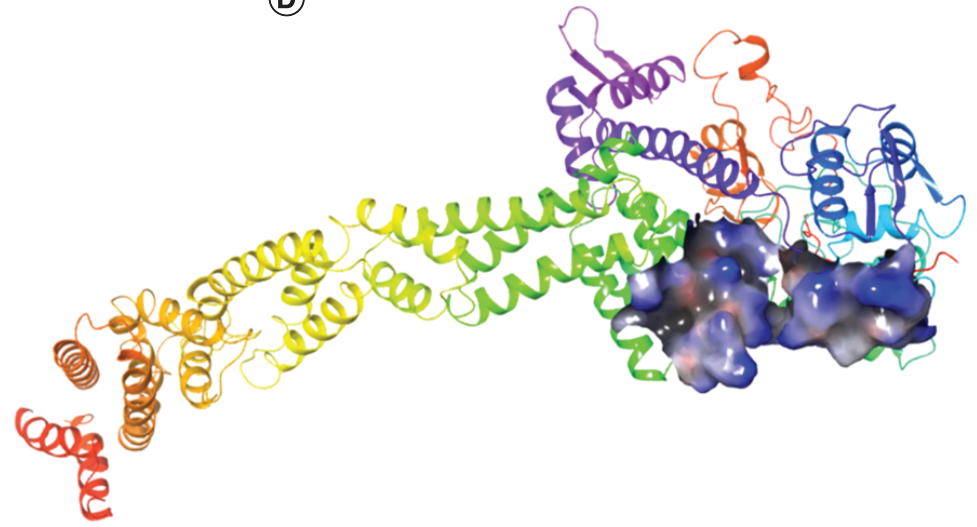

(F)

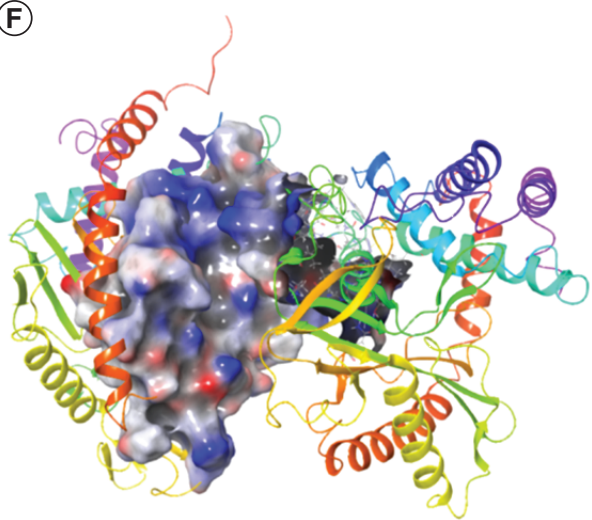

Figure 8. Positive patches of DNA binding proteins could be targets for suramin interactions. Not drawn to scale. (A) DNA (PDB 3RN2 [48]); (B) RNA (PDB 5E3H [49]); (C) AIM2 (PDB 3RN2 [48]); (D) CUL1 (PDB 1LDJ [50]). The basic cleft where suramin was demonstrated to bind is shown as an electrostatic potential surface [34]. (E) RIG-1 (PDB 5E3H [49]); (F) human cGAS (PDB 4LEV [16]). Figures are shown with an electrostatic potential surface which is confined to the DNA binding region (C-F) or suramin binding region (D) of the protein models.

\section{Future perspective}

The cGAS-STING pathway plays important roles in various autoimmune diseases and the past year has witnessed increasing interest by research groups to identify cGAS inhibitors for treating autoimmune diseases. We predict that various groups will report new cGAS inhibitors with cellular and animal activity. Suramin is already an approved drug but has more room for improvement. Analogs of suramin that bind better to cGAS and also with enhanced 
cell permeation properties could have applications in the management of various inflammatory diseases. We are actively working on such analogs and will report in due course.

\section{Summary points}

- Suramin inhibits cGAS, potentially via binding to its DNA binding site.

- Discovery of suramin as CGAS inhibitor from compound library.

- Suramin facilitated displacement of DNA from hcGAS.

- Suramin disrupts dsDNA/cGAS binding.

- IFN- $\beta$ levels produced by THP-1 cells are reduced by suramin.

- Functional modulation of hcGAS activity by suramin.

- Suramin can enter the cell and attenuate cGAS activity rather than simply affect DNA transfection efficiency.

- Functional modulation of hcGAS activity by suramin.

- Suramin inhibits cGAS and has been shown to enter cells by an uncharacterized mechanism.

- Suramin may be a nucleic acid mimic.

- Suramin disrupts dsDNA/cGAS binding and downregulates the type-l interferon response.

- Suramin and/or analogs have the potential to be used to treat chronic inflammation.

- Suramin analogs with better cell permeability should be pursued as anti-inflammatory agents.

\section{Supplementary data}

To view the supplementary data that accompany this paper please visit the journal website at: www.future-science.com/doi/full/ 10.4155/fmc-2017-0322

Financial \& competing interests disclosure

The authors have no relevant affiliations or financial involvement with any organization or entity with a financial interest in or financial conflict with the subject matter or materials discussed in the manuscript. This includes employment, consultancies, honoraria, stock ownership or options, expert testimony, grants or patents received or pending, or royalties.

No writing assistance was utilized in the production of this manuscript.

\section{Open access}

This work is licensed under the Attribution-NonCommercial-NoDerivatives 4.0 Unported License. To view a copy of this license, visit http://creativecommons.org/licenses/by-nc-nd/4.0/

\section{References}

Papers of special note have been highlighted as: $\bullet$ of interest; $\bullet \bullet$ of considerable interest

1. Chen Q, Sun L, Chen ZJ. Regulation and function of the cGAS-STING pathway of cytosolic DNA sensing. Nat. Immunol. 17, 1142 (2016).

- An informative review article detailing the cGAS-STING pathway for the sensing of cytosolic DNA.

2. Sun LJ, Wu JX, Chen ZJ. Cyclic GMP-AMP synthase (cGAS) is a cytosolic DNA sensor that activates type I interferon pathway by generating a second messenger. J. Immunol. 339(6121), 786-791 (2013).

3. Dey RJ, Dey B, Zheng Y et al. Inhibition of innate immune cytosolic surveillance by an M. tuberculosis phosphodiesterase. Nat. Chem. Biol. 13(2), 210-217 (2017).

4. Storek KM, Gertsvolf NA, Ohlson MB, Monack DM. cGAS and Ifi204 cooperate to produce type I IFNs in response to francisella infection. J. Immunol. 194(7), 3236-3245 (2015).

5. Gray EE, Treuting PM, Woodward JJ, Stetson DB. Cutting edge: cGAS is required for lethal autoimmune disease in the Trex1-deficient mouse model of Aicardi-Goutieres syndrome. J. Immunol. 195(5), 1939-1943 (2015).

-. Demonstrates that cGAS is a key driver of autoimmune disease using TREX1-deficient mice, which develop multi-organ inflammation, and found that when cGAS was knocked out, the mice showed no signs of inflammation.

6. Gao DX, Li T, Li XD et al. Activation of cyclic GMP-AMP synthase by self-DNA causes autoimmune diseases. Proc. Natl Acad. Sci. USA 112(42), e5699-e5705 (2015).

7. Song J. A novel TLR4-mediated signaling pathway leading to IL-6 responses in human bladder epithelial cells. PLoS Pathog. 3(4), (2007).

8. De Oliviera Nascimento L, Massari P, Wetzler L. The role of TLR2 in infection and immunity. Front. Immunol. 3(79), 1-17 (2012). 
9. Libermann TA, Baltimore D. Activation of interleukin-6 gene expression through the NF-kappa B transcription factor. Mol. Cell. Biol. 10(5), 2327-2334 (1990).

10. Ratsimandresy R, Dorfleutner A, Stehlik C. An update on PYRIN domain-containing pattern recognition receptors: from immunity to pathology. Front. Immunol. 4, 440 (2013).

11. Edye Michelle E, Walker Lauren E, Sills Graeme J, Allan Stuart M, Brough D. Epilepsy and the inflammasome: targeting inflammation as a novel therapeutic strategy for seizure disorders. Inflammasome 1(1), 36-43 (2014).

12. West AP, Shadel GS. Mitochondrial DNA in innate immune responses and inflammatory pathology. Nat. Rev. Immunol. 17, 363 (2017).

13. Erdal E, Haider S, Rehwinkel J, Harris AL, McHugh PJ. A prosurvival DNA damage-induced cytoplasmic interferon response is mediated by end resection factors and is limited by Trex1. Genes Dev. 31(4), 353-369 (2017).

14. Yang YG, Lindahl T, Barnes DE. Trex1 exonuclease degrades ssDNA to prevent chronic checkpoint activation and autoimmune disease. Cell 131(5), 873-886 (2007).

15. Stetson DB, Ko JS, Heidmann T, Medzhitov R. Trex1 prevents cell-intrinsic initiation of autoimmunity. Cell 134(4), 587-598 (2008).

16. Li X, Shu C, Yi G et al. Cyclic GMP-AMP synthase is activated by double-stranded DNA-induced oligomerization. Immunity 39(6), 1019-1031 (2013).

17. Barber GN. STING-dependent cytosolic DNA sensing pathways. Trends Immunol. 35(2), 88-93 (2014).

18. Lam E, Stein S, Falck-Pedersen E. Adenovirus detection by the cGAS/STING/TBK1 DNA sensing cascade. J. Virol. 88(2), 974-981 (2014).

19. Honda K, Takaoka A, Taniguchi T. Type I interferon [corrected] gene induction by the interferon regulatory factor family of transcription factors. Immunity 25(3), 349-360 (2006).

20. Panne D, Maniatis T, Harrison SC. Crystal structure of ATF-2/c-Jun and IRF-3 bound to the interferon-beta enhancer. EMBO J. 23(22), 4384-4393 (2004).

21. Zhao B, Shu C, Gao X et al. Structural basis for concerted recruitment and activation of IRF-3 by innate immune adaptor proteins. Proc. Natl Acad. Sci. USA 113(24), e3403-e3412 (2016).

22. Fye JM, Orebaugh CD, Coffin SR, Hollis T, Perrino FW. Dominant mutations of the TREX1 exonuclease gene in lupus and Aicardi-Goutières syndrome. J. Biol. Chem. 286(37), 32373-32382 (2011).

23. An J, Woodward JJ, Sasaki T, Minie M, Elkon KB. Cutting edge: antimalarial drugs inhibit IFN-beta production through blockade of cyclic GMP-AMP synthase-DNA interaction. J. Immunol. 194(9), 4089-4093 (2015).

- In silico screening of mouse cGAS/DNA identified cGAMP synthesis inhibitors which were found to localize to the minor groove of DNA between the cGAS/DNA interface.

24. Vincent J, Adura C, Gao P et al. Small molecule inhibition of cGAS reduces interferon expression in primary macrophages from autoimmune mice. Nat. Commun. 8(1), 750 (2017).

-. Demonstrates that inhibition of cGAS reduced cGAS-mediated interferon upregulation, but had no effect on inflammatory pathways independent of cGAS. This indicated the potency and selectivity of the inhibitor.

25. Hall J, Brault A, Vincent F et al. Discovery of PF-06928215 as a high affinity inhibitor of cGAS enabled by a novel fluorescence polarization assay. PLoS ONE 12(9), e0184843 (2017).

26. Zheng Y, Zhou J, Sayre DA, Sintim HO. Identification of bromophenol thiohydantoin as an inhibitor of DisA, a c-di-AMP synthase, from a 1000 compound library, using the coralyne assay. Chem. Commun. 50(76), 11234-11237 (2014).

27. Opoku-Temeng C, Sintim HO. Potent inhibition of cyclic diadenylate monophosphate cyclase by the antiparasitic drug, suramin. Chem. Commun. 52(19), 3754-3757 (2016).

28. Opoku-Temeng C, Dayal N, Miller J, Sintim HO. Hydroxybenzylidene-indolinones, c-di-AMP synthase inhibitors, have antibacterial and anti-biofilm activities and also re-sensitize resistant bacteria to methicillin and vancomycin. RSC Adv. 7(14), 8288-8294 (2017).

29. Kranzusch PJ, Lee ASY, Berger JM, Doudna JA. Structure of human cGAS reveals a conserved family of second-messenger enzymes in innate immunity. Cell Rep. 3(5), 1362-1368 (2013).

30. Zdanov AS, Phan J, Evdokimov AG et al. Tobacco etch virus protease: crystal structure of the active enzyme and its inactive mutant. Russ. J. Bioorg. Chem. 29(5), 415-417 (2003).

31. Zhang X, Shi H, Wu J et al. Cyclic GMP-AMP containing mixed phosphodiester linkages is an endogenous high-affinity ligand for STING. Mol. Cell. 51(2), 226-235 (2013).

32. Wang ZS, Liu YL, Mi N, Duan DY. Intracellular DNA sensing pathway of cGAS-cGAMP is decreased in human newborns and young children. Mol. Immunol. 87, 76-85 (2017).

33. Safley SA, Villinger F, Jackson EH, Tucker-Burden C, Cohen C, Weber CJ. Interleukin-6 production and secretion by human parathyroids. Clin. Exp. Immunol. 136(1), 145-156 (2004).

34. Wu K, Chong RA, Yu Q et al. Suramin inhibits cullin-RING E3 ubiquitin ligases. Proc. Natl Acad. Sci. USA 113(14), e2011-e2018 (2016). 
35. Ilg $\mathrm{T}$. Investigations on the molecular mode of action of the novel immunostimulator ZelNate: activation of the cGAS-STING pathway in mammalian cells. Mol. Immunol. 90(Suppl. C), 182-189 (2017).

36. Alyoussef A. Suramin attenuated inflammation and reversed skin tissue damage in experimentally induced atopic dermatitis in mice. Inflamm. Allergy Drug Targets 13(6), 406-410 (2015).

37. Li XD, Wu J, Gao D, Wang H, Sun L, Chen ZJ. Pivotal roles of cGAS-cGAMP signaling in antiviral defense and immune adjuvant effects. Science 341(6152), 1390-1394 (2013).

38. Huang SS, Koh HA, Huang JS. Suramin enters and accumulates in low pH intracellular compartments of v-sis-transformed NIH 3T3 cells. FEBS Lett. 416(3), 297-301 (1997).

39. Baghdiguian S, Boudier JL, Boudier JA, Fantini J. Intracellular localisation of suramin, an anticancer drug, in human colon adenocarcinoma cells: a study by quantitative autoradiography. Eur. J. Cancer 32a(3), 525-532 (1996).

40. Dhar S, Gullbo J, Csoka K et al. Antitumour activity of suramin analogues in human tumour cell lines and primary cultures of tumour cells from patients. Eur. J. Cancer 36(6), 803-809 (2000).

41. Stein CA. Suramin: a novel antineoplastic agent with multiple potential mechanisms of action. Cancer Res. 53(10 Suppl.), 2239-2248 (1993).

42. Galligan CL, Pennell LM, Murooka TT et al. Interferon-beta is a key regulator of proinflammatory events in experimental autoimmune encephalomyelitis. Mult. Scler. 16(12), 1458-1473 (2010).

43. Aliprantis AO, Yang R-B, Mark MR et al. Cell activation and apoptosis by bacterial lipoproteins through toll-like receptor-2. Science 285(5428), 736-739 (1999).

44. Gantier MP, Williams BRG. The response of mammalian cells to double-stranded RNA. Cytokine Growth Factor Rev. 18(5-6), 363-371 (2007).

45. Gil J, García MA, Gomez-Puertas P et al. TRAF family proteins link PKR with NF-kB activation. Mol. Cell. Biol. 24(10), 4502-4512 (2004).

46. Komuro A, Horvath CM. RNA- and virus-independent inhibition of antiviral signaling by RNA helicase LGP2. J. Virol. 80(24), 12332-12342 (2006).

47. Ma F, Li B, Liu S-Y et al. Positive feedback regulation of type I IFN production by the IFN-inducible DNA sensor cGAS. J. Immunol. 194(4), 1545-1554 (2015).

48. Jin T, Perry A, Jiang J et al. Structures of the HIN domain: DNA complexes reveal ligand binding and activation mechanisms of the AIM2 inflammasome and IFI16 receptor. Immunity 36(4), 561-571 (2012).

49. Jiang F, Ramanathan A, Miller MT et al. Structural basis of RNA recognition and activation by innate immune receptor RIG-I. Nature 479423 (2011).

50. Zheng N, Schulman BA, Song L et al. Structure of the Cul1-Rbx1-Skp1-F boxSkp2 SCF ubiquitin ligase complex. Nature 416, 703 (2002).

51. Ren P, Zheng Y, Wang W et al. Suramin interacts with the positively charged region surrounding the 5-fold axis of the EV-A71 capsid and inhibits multiple enterovirus A. Sci. Rep. 7, 42902 (2017).

52. De Clercq E. Suramin: a potent inhibitor of the reverse transcriptase of RNA tumor viruses. Cancer Lett. 8(1), 9-22 (1979).

53. De Clercq E. Suramin in the treatment of AIDS: mechanism of action. Antiviral Res. 7(1), 1-10 (1987).

54. Balzarini J, Mitsuya H, De Clercq E, Broder S. Comparative inhibitory effects of suramin and other selected compounds on the infectivity and replication of human T-cell lymphotropic virus (HTLV-III)/lymphadenopathy-associated virus (LAV). Int. J. Cancer 37(3), 451-457 (1986).

55. Crow YJ, Hayward BE, Parmar R et al. Mutations in the gene encoding the $3^{\prime}-5^{\prime}$ DNA exonuclease TREX1 cause Aicardi-Goutières syndrome at the AGS1 locus. Nat. Genet. 38, 917 (2006).

56. Barizzone N, Monti S, Mellone S et al. Rare variants in the TREX1 gene and susceptibility to autoimmune diseases. BioMed Res. Int. 2013, 6 (2013).

57. Kerur N, Fukuda S, Banerjee D et al. cGAS drives noncanonical-inflammasome activation in age-related macular degeneration. Nat. Med. 24, 50 (2017)

58. Dou Z, Ghosh K, Vizioli MG et al. Cytoplasmic chromatin triggers inflammation in senescence and cancer. Nature 550(7676), 402-406 (2017)

59. Yang H, Wang H, Ren J, Chen Q, Chen ZJ. cGAS is essential for cellular senescence. Proc. Natl Acad. Sci. USA 114(23), e4612-e4620 (2017).

60. Glück S, Guey B, Gulen MF et al. Innate immune sensing of cytosolic chromatin fragments through cGAS promotes senescence. Nat. Cell Biol. 19, 1061 (2017).

61. Gallego-Marin C, Schrum JE, Andrade WA et al. Cyclic GMP-AMP synthase is the cytosolic sensor of plasmodium falciparum genomic DNA and activates type I IFN in malaria. J. Immunol. 200(2), 768-774 (2017). 
62. King KR, Aguirre AD, Ye Y-X et al. IRF3 and type I interferons fuel a fatal response to myocardial infarction. Nat. Med. 23, 1481 (2017).

63. Cao D, Schiattarella GG, Villalobos E et al. Cytosolic DNA sensing promotes macrophage transformation and governs myocardial ischemic injury. Circulation 137(9), doi:10.1161/circulationaha.117.031046 (2018). 
